\section{Gastric full-thickness suturing following NOTES procedures for closure of the access site to the peritoneal cavity}

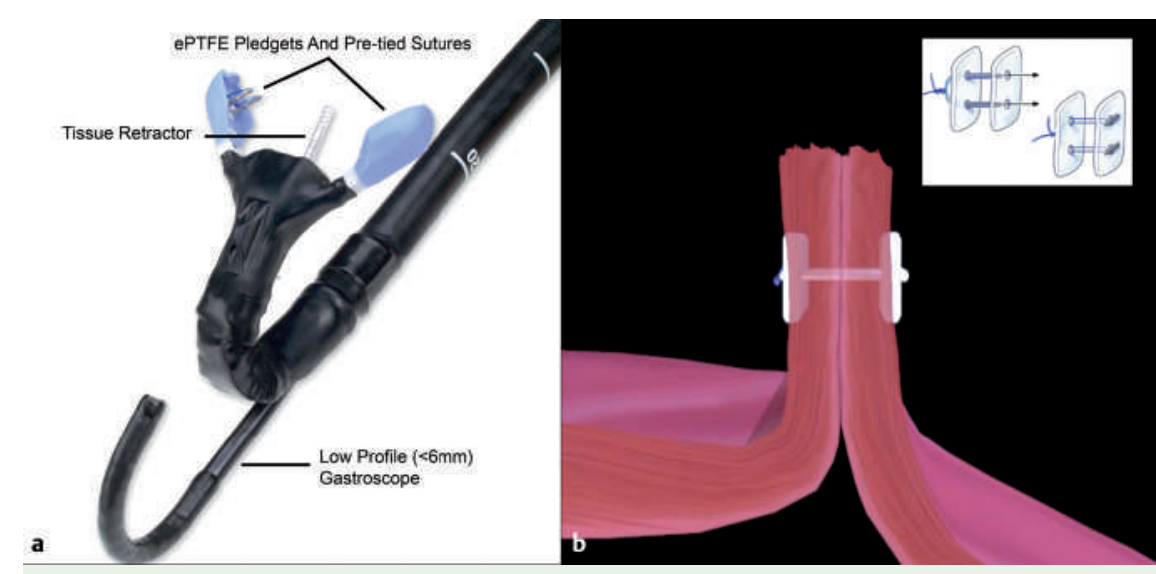

Fig. 1 Plicator device distal end. a The Plicator is retroflexed and suturing under visualization through a low profile gastroscope $(<6 \mathrm{~mm})$ is possible. $\mathbf{b}$ Schematic illustration of the endoscopic fullthickness suturing of the NOTES access site to the peritoneal cavity and the Plicator sutures.
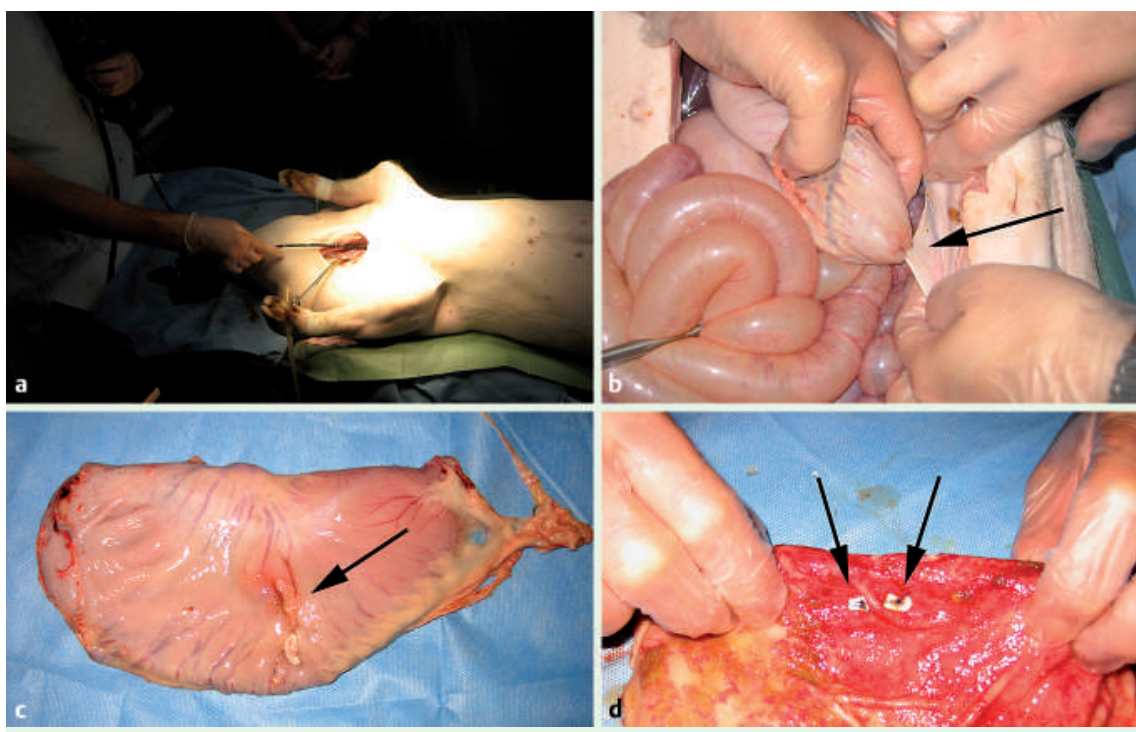

Fig. 2 a Surgically created jugular access to the esophagus after euthanization was necessary to gain access to the gastric wall opening. $\mathbf{b}$ Peritoneal serosa was found incorporated into the gastric closure after full-thickness suturing. $\mathbf{c}$ Exoluminal view after gastrectomy of the suturing site with incorporated peritoneal serosa. $\mathbf{d}$ Endoluminal view of the suturing site.
Since the first publication on Natural Orifice Transluminal Endoscopic Surgery (NOTES) in 2004 research interest has grown steadily [1-2]. It seems feasible that endoscopic surgery might be performed via a transgastric, transvaginal, or transcolonic route of access to the peritoneal cavity [2-4]. There is consensus on the criticality of a secure closure following NOTES procedures [2-4]. By means of endoscopic full-thickness plication (Plicator ${ }^{\circledR}$, NDO Surgical, USA), expeditious and easy placement of transmural sutures can be facilitated [5].

To evaluate the feasibility for gastric wall suturing, a standard nonmodified Plicator device and 4-mm sutures ( $\bullet$ Fig. 1) were used in two domestic swine following NOTES cholecystectomy.

Due to the long snout and neck, the 60$\mathrm{cm}$ Plicator device failed to gain transoral access to the gastric lesions and surgically created access to the esophagus was established ( $\bullet$ Fig. 2 a). Procedure time for endoscopic placement of two sutures in the first swine was 19 minutes. Following the procedures laparotomy was performed. In the first case, the NOTES access site was not closed properly mainly due to gastric debris and poor visibility of the NOTES access site to the peritoneal cavity. Therefore, in the second swine extended gastric lavage was carried out, and complete occlusion was achieved within 17 minutes utilizing two sutures. Peritoneal serosa was found to be incorporated into the suture in the first case during laparotomy ( $\mathbf{F i g .} \mathbf{2} \mathbf{b}-\mathbf{c}$ ). No damage to adjacent organs was found in either case. Incorporated peritoneal serosa or damage to adjacent organs might represent a peril of transmural suturing but a more reliable suture might be achieved compared with endoluminal clipping techniques ( $\bullet$ Fig. 2 d). Therefore, this technique seems worthy of wider evaluation. A modified thinner and longer device and the availability of resorbable sutures could further improve the applicability of the Plicator in combination with NOTES. 


\section{Acknowledgments}

$\nabla$

Material support (Plicator device and sutures) for this experiment was provided by NDO Surgical Inc., USA

Endoscopy_UCTN_Code_TTT_1AO_2AI

Endoscopy_UCTN_Code_TTT_1AO_2AN

\section{D. von Renteln ${ }^{1}$, G. Kaehler ${ }^{2}$,}

A. Eickhoff ${ }^{3}$, B. Riecken ${ }^{1}$, K. Caca ${ }^{1}$

${ }^{1}$ Medizinische Klinik I, Klinikum Ludwigsburg, Ludwigsburg, Germany

2 Sektion Endoskopie und Sonographie der Chirurgischen Universitätsklinik, Universitätsklinik Mannheim, Mannheim, Germany

3 Medizinische Klinik C, Klinikum Ludwigshafen, Ludwigshafen, Germany

\section{References}

1 Kalloo AN, Singh VK, Jagannath SB et al. Flexible transgastric peritoneoscopy: a novel approach to diagnostic and therapeutic interventions. Gastrointest Endosc 2004; 60 : $114-117$

2 Voermans RP, Van Berge Henegouwen MI, Fockens $P$. Natural orifice transluminal endoscopic surgery (NOTES). Endoscopy 2007; 39: 1013 - 1017

3 Bowman DE. ASGE/SAGES Working Group on natural orifice transluminal endoscopic surgery: White Paper October 2005. Gastrointest Endosc 2006; 63: 199-203

4 Swain P. A justification for NOTES - natural orifice translumenal endosurgery. Gastrointest Endosc 2007; 65: 514-516

5 von Renteln D, Schmidt A, Riecken B, Caca K. Gastric full-thickness suturing during endoscopic mucosal resection and for treatment of gastric wall defects. Gastrointest Endosc; Epub ahead of print
Bibliography

DOI $10.1055 / \mathrm{s}-2007-995574$

Endoscopy 2008; 40: E99-E100

(c) Georg Thieme Verlag KG Stuttgart · New York . ISSN 0013-726X

\section{Corresponding author}

\section{K. Caca, MD}

Medizinische Klinik I

Klinikum Ludwigsburg

Posilipostr. 4

71640 Ludwigsburg

Germany

karel.caca@kliniken-lb.de 